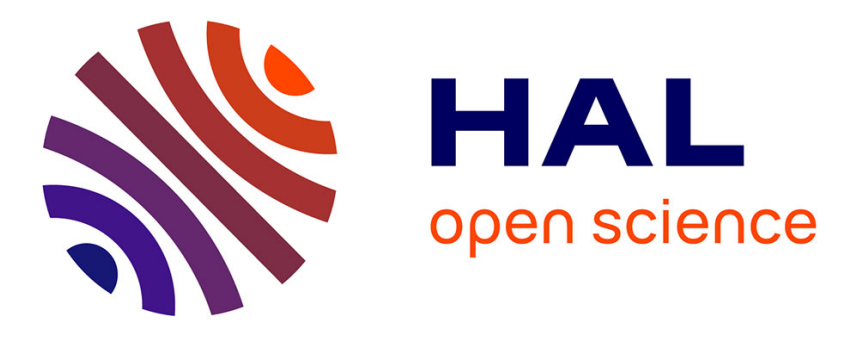

\title{
Platelet protease nexin-1, a serpin that strongly influences fibrinolysis and thrombolysis.
}

Yacine Boulaftali, Benoît Ho-Tin-Noe, Ana Pena, Stéphane Loyau, Laurence

Venisse, Déborah François, Benjamin Richard, Véronique Arocas, Jean-Philippe Collet, Martine Jandrot-Perrus, et al.

\section{To cite this version:}

Yacine Boulaftali, Benoît Ho-Tin-Noe, Ana Pena, Stéphane Loyau, Laurence Venisse, et al.. Platelet protease nexin-1, a serpin that strongly influences fibrinolysis and thrombolysis.: Platelet Protease Nexin-1 Is Antithrombolytic. Circulation, 2011, 123 (12), pp.1326-34. 10.1161/CIRCULATIONAHA.110.000885 . inserm-00583943

\section{HAL Id: inserm-00583943 https://www.hal.inserm.fr/inserm-00583943}

Submitted on 7 Oct 2011

HAL is a multi-disciplinary open access archive for the deposit and dissemination of scientific research documents, whether they are published or not. The documents may come from teaching and research institutions in France or abroad, or from public or private research centers.
L'archive ouverte pluridisciplinaire HAL, est destinée au dépôt et à la diffusion de documents scientifiques de niveau recherche, publiés ou non, émanant des établissements d'enseignement et de recherche français ou étrangers, des laboratoires publics ou privés. 


\section{PLATELET PROTEASE NEXIN-1, A SERPIN THAT STRONGLY INFLUENCES FIBRINOLYSIS AND THROMBOLYSIS.}

Boulaftali et al. Platelet protease nexin-1 is antithrombolytic

Yacine Boulaftali, ${ }^{1} \mathrm{PhD}$; Benoit Ho-Tin-Noe ${ }^{1}, \mathrm{PhD}$; Ana Pena ${ }^{2}, \mathrm{PhD}$; Stéphane Loyau ${ }^{1}$, BScTech ; Laurence Venisse ${ }^{1}$, BScTech ; Déborah François ${ }^{1}$,MSc ; Benjamin Richard ${ }^{1}$, $\mathrm{PhD}$;Véronique Arocas ${ }^{1}$, PhD ; Jean-Philippe Collet ${ }^{2}, \mathrm{MD}, \mathrm{PhD}$; Martine Jandrot-Perrus ${ }^{1}$, MD, PhD and Marie-Christine Bouton ${ }^{1}, \mathrm{PhD}$.

${ }^{1}$ INSERM, U698, Paris ; CHU Xavier Bichat ; Université Paris 7, 75877 France

22INSERM, U937, Paris, Institut de Cardiologie, Hôpital de la Pitié-Salpêtrière, 75013 France

Address correspondence to: Marie-Christine BOUTON

Unité INSERM U698, CHU Xavier Bichat

46 rue Henri Huchard 75877 Paris Cedex 18, France

Tel: 33 (1) 40.25.75.32

Fax: 33 (1) 40.25.86.02

E-Mail: marie-christine.bouton@inserm.fr

Total word count: 5983

Journal Subject Codes: Thrombosis [92][160] [175] 


\section{Abstract}

Background- Protease nexin-1 (PN-1) is a serpin that inhibits plasminogen activators, plasmin and thrombin. $\mathrm{PN}-1$ is barely detectable in plasma, but we have recently shown that PN-1 is present within the alpha-granules of platelets.

Methods and Results- In this study, the role of platelet PN-1 in fibrinolysis was investigated using human platelets incubated with a blocking antibody and platelets from PN-1-deficient mice. We showed by using fibrin-agar zymography and fibrin matrix that platelet PN-1 inhibited both the generation of plasmin by fibrin-bound tPA, and the activity of fibrin-bound plasmin itself. Rotational thromboelastometry $\left(\right.$ ROTEM $\left.^{\circledR}\right)$ and laser scanning confocal microscopy were used to demonstrate that PN-1 blockade or deficiency resulted in increased clot lysis and in an acceleration of the lysis front. PN-1 is thus a major determinant of the lysis-resistance of platelet-rich clots (PRCs). Moreover, in an original murine model in which thrombolysis induced by tPA can be measured directly in situ, we observed that vascular recanalization was significantly increased in PN-1-deficient mice. Surprisingly, general physical health, after tPA-induced thrombolysis, was much better in PN-1-deficient than in wild-type mice.

Conclusion- Our results reveal that platelet PN-1 can be considered as a new important regulator of thrombolysis in vivo. Inhibition of $\mathrm{PN}-1$ is thus predicted to promote endogenous and exogenous t-PA-mediated fibrinolysis, and may enhance the therapeutic efficacy of thrombolytic agents. 


\section{Introduction}

Vascular injury and subsequent thrombus formation are key events in the pathogenesis of atherothrombosis and venous thromboembolism. The serine proteases, urokinase- and tissue-type plasminogen activators (uPA and tPA respectively), generate plasmin which drives fibrinolysis. The thrombolytic actions of these proteases are critical for clot dissolution. Their properties have numerous therapeutic applications, including fibrinolysis for ST elevation myocardial infarction (STEMI). Direct recanalization of an occluded vessel by primary angioplasty became the preferred reperfusion strategy in STEMI patients.

Thrombolysis remains however, an option of reperfusion therapy in early STEMI presenters. Despite early administration of recombinant tPA in STEMI presenters, fibrinolysis fails to achieve myocardial reperfusion in one out of two patients and is associated with poor clinical outcome $^{1}$. This phenomenon is of considerable clinical importance in the setting of acute myocardial infarction, because early restoration of normal blood flow is strongly associated with improved survival. A few factors have been identified to be involved in this interindividual heterogeneity, such as age, delay between symptom onset and fibrinolytic therapy, smoking habit, infarct size and site ${ }^{2}$.

Plasminogen activator inhibitor type-1 (PAI-1) is a serine protease inhibitor which is present in plasma and in platelet $\alpha$-granules. An increased plasma concentration of PAI- 1 has been associated with recurrent myocardial infarction ${ }^{3,4}$. In humans, platelet PAI-1 is assumed to be a major contributor to the stabilization of the thrombus, by inhibiting endogenous fibrinolysis $^{5,6}$. However, platelets have also been shown to inhibit fibrinolysis by PAI-1independent mechanisms ${ }^{7}$, and the individual role of other serpins, in the thrombolytic process has not yet been defined. Protease nexin-1 (PN-1), also known as SERPINE2, deserves special attention since it has been shown in vitro to inhibit significantly uPA, tPA and plasmin. PN-1 is barely detectable in plasma ${ }^{8}$ but is produced by various cell types ${ }^{9}$, and 
interestingly, stored in the $\alpha$-granules of platelets ${ }^{10}$. Because of its action on proteases of the plasminergic system, we hypothesized that platelet $\mathrm{PN}-1$ may play a prominent role in the process of thrombolysis resistance.

The present paper evaluates, by in vitro and ex vivo studies, the role of platelet PN-1 in platelet-rich clot (PRC) lysis. Moreover, we have developed a murine model of thrombolysis and applied it to wild-type and PN-1-deficient mice to test the hypothesis that PN-1 inhibits thrombolysis initiated by recombinant tPA. Thus, PN-1 may be a potential target to improve the therapeutic applications of thrombolytic agents. 


\section{Materials and methods}

\section{Animals}

PN-1-deficient mice (PN-1-/-) come from Pr D. Monard’s laboratory (FMI, Basel, Switzerland) and were back-crossed for 12 generations into the C57BL/6 line ${ }^{11}$. Experimental animals were 8-16 weeks of age. Heterozygous mating generated PN-1-/- and wild-type mice (WT). Mice were bred and maintained in our own laboratory (Paris, France). All animals were genotyped by PCR. All experiments were performed in accordance with European legislation on the protection of animals.

\section{Methods}

\section{Preparation of washed platelets}

Human platelets

Human blood from healthy adult volunteers was collected into 1/10 vol. ACD-A (38 mM citric acid, $60 \mathrm{mM}$ sodium citrate, $136 \mathrm{mM}$ glucose). Washed platelets were isolated as previously described $^{12}$.

Mouse platelets

Blood was collected from anesthetized mice by cardiac puncture into syringes containing 1/10 vol. ACD-C (130 mM citric acid, $124 \mathrm{mM}$ sodium citrate, $110 \mathrm{mM}$ glucose). Washed platelets were isolated as previously described ${ }^{10}$.

\section{Binding of tPA and plasmin to fibrin matrices, and measurement of plasmin generation or activity.}

Fibrin matrices in 96-well plates were prepared as previously described ${ }^{13}$. The functionality of this fibrin surface was determined by measuring the activation of plasminogen by fibrin- 
bound t-PA, or the activity of fibrin-bound plasmin itself (See the online-only Method supplement).

\section{SDS-polyacrylamide gel electrophoresis and zymography.}

Platelets $\left(5 \times 10^{8} / \mathrm{mL}\right.$ in reaction buffer) were activated by PAR1-AP (PAR1-activating peptide, SFLLRN, NeoMPS) (50 $\mu \mathrm{M})$ for human platelets or by PAR4-AP (PAR4-activating peptide, AYPGKF, NeoMPS) $(250 \mu \mathrm{M})$ for mouse platelets, for 30 minutes at $37^{\circ} \mathrm{C}$. Control samples were obtained by incubating platelets for the same time with buffer. At the end of the incubation, samples were centrifuged and the supernatants (secreted fraction) were removed for analysis. The secreted fractions were incubated with recombinant tPA (10 IU/ml) or plasmin $(0.25 \mu \mathrm{M})$ for 30 minutes at $37^{\circ} \mathrm{C}$ in the presence or absence of the blocking anti-PN1 (generous gift from Dr D.Hantai, Inserm U582, Paris) or anti-PAI-1 IgGs (MA-33B8-307; Molecular Innovations). Proteins were first separated on a 10\% SDS-polyacrylamide gel. After incubation with $2 \%$ Triton X-I00, the gel was then overlaid on a fibrin-plasminogen (200 nM)-agar gel, for tPA activity measurement, or on a fibrin-agar gel for plasmin activity, as previously described ${ }^{14}$. Zymograms were allowed to develop at $37^{\circ} \mathrm{C}$ during 24 hours and photographed at regular intervals using dark-ground illumination. Zymograms were stained with blue-coomassie ${ }^{15}$.

\section{Clot formation and fibrinolysis ex vivo}

Human PRP was obtained from citrated blood by centrifugation at 120g during 15 minutes. PRP was adjusted at $10^{8}$ platelets $/ \mathrm{ml}$ in platelet free plasma and supplemented with $75 \mu \mathrm{g} / \mathrm{ml}$ FITC-fibrinogen. For mouse PRCs, citrated human platelet-free plasma was mixed with murine washed platelets to a concentration of $8 \times 10^{8} / \mathrm{ml}$. Samples were incubated with irrelevant-IgG or the blocking anti-PN-1 IgG or/and anti-PAI-1 IgG both at $100 \mu \mathrm{g} / \mathrm{ml}$ and 
recalcified with $10 \mathrm{mM} \mathrm{CaCl}_{2}$ in glass tubes. After retraction, clots were removed, blotted and weighed. To assess fibrinolysis, clots were incubated in Hanks buffer (Sigma) for 24 hours at $37^{\circ} \mathrm{C}$. The supernatant was removed, and the fluorescence released from the clot was measured in a spectrofluorometer ${ }^{16}$. The remaining clots were blotted and reweighed to calculate the loss of clot weight, and then were totally dissolved to calculate the fluorescence remained in the clot.

\section{Fibrinolysis experiments: microscopic lysis velocity by laser scanning confocal microscopy}

Citrated human or mice PRP was adjusted at $10^{8}$ platelets $/ \mathrm{ml}$ and supplemented with Alexa 488-fibrinogen (Invitrogen). Human PRP was incubated with control IgG (Jackson immunoresearch) or blocking anti-PN-1 IgG (100 $\mu \mathrm{g} / \mathrm{ml})$ and PRCs were obtained by adding tissue factor (TF, Innovin 1/5 (v/v)) (Diagnostica Stago) and $10 \mathrm{mM} \mathrm{CaCl}_{2}$ in microchambers as previously described ${ }^{17}$. PRP from WT or PN-1 -/- mice was clotted in the same conditions. Clots were scanned with a LEICA confocal laser scanning microscope linked to a Leica inverted microscope equipped with a $\times 63$ water immersion objective. Scans were collected in a format of $512 \times 512$ pixels with 1024 gradations of intensity. Recombinant tissue plasminogen activator (rtPA, 26nM) (Alteplase, Boerhinger) was loaded at the edge of the labelled PRC. The edge of the clot was visualized with the confocal microscope set up in the reflection mode. Scanning was performed at a magnification $125 \times 125 \mu$ m every 15 seconds for 30 minutes. The velocity of the lysis front was determined from confocal microscope images and analysed with image $\mathrm{J}$ software.

\section{ROTEM $^{\circledR}$ Modified Rotation Thrombelastogram Analyzer}


Citrated PRP was obtained and adjusted at $10^{8}$ platelets $/ \mathrm{ml}$ as described above. ROTEM ${ }^{\circledR}$ analysis was performed in pre-warmed ROTEM ${ }^{\circledR}$ cup containing $300 \mu$ l of PRP in presence of control IgG or the blocking anti-PN-1 or/and anti-PAI-1 IgG both at $100 \mu \mathrm{g} / \mathrm{ml}$. Clotting was initiated by the addition of TF (Innovin 1/5 (v/v)), $\mathrm{CaCl}_{2}(10 \mathrm{mM})$. Fibrinolysis was initiated by the addition of human r-tPA (0.5 nM) (Alteplase, Boerhinger) or mouse r-tPA (30 nM) (Molecular Innovation). The fibrinolytic response by rtPA was assessed using ROTEM ${ }^{\circledR}$ software, thereby providing the lysis rate at 60 minutes in each condition.

\section{Dorsal skinfold chamber}

Dorsal skinfold chambers were implanted in 10- to 12-week-old mice (25 to $30 \mathrm{~g}$ body weight) anesthetized by intraperitoneal injection of $100 \mathrm{mg} / \mathrm{kg}$ ketamine and $10 \mathrm{mg} / \mathrm{kg}$ xylazine in saline solution as previously described ${ }^{18}$. Briefly, a patch of dorsal hair was removed, and two titanium frames were positioned so as to sandwich the extended double layer of skin. One layer of betadine-cleaned skin was completely removed in a circular area of $13 \mathrm{~mm}$ in diameter, and the remaining layer, consisting of epidermis, subcutaneous tissue, and striated skin muscle, was covered with a 12-mm glass coverslip incorporated in the frame. Following surgery, mice were injected subcutaneously with buprenorphine $(0.05 \mathrm{mg} / \mathrm{kg})$ and then again 8-12 h later. The animals tolerated the chambers well and showed no sign of discomfort. After a 48 h-period of recovery from surgery, preparations fulfilling the criteria of intact microcirculation and showing no signs of inflammation were utilized for thrombosis and thrombolysis experiments.

\section{Real-time intravital imaging of thrombus formation and thrombolysis.}

Mice were anesthetized with $100 \mathrm{mg} / \mathrm{kg}$ ketamine and $10 \mathrm{mg} / \mathrm{kg}$ xylazine and vascular injury was induced by placing a Whatman filter paper strip $(1 \times 0.5 \mathrm{~mm})$ saturated with $15 \% \mathrm{FeCl}_{3}$ 
(Sigma) over venules (ranging from 130 to $160 \mu \mathrm{m}$ diameter) in dorsal skinfold chambers for 3 minutes. Thrombus formation following vessel injury was examined in real-time by monitoring the accumulation of rhodamine 6G (Sigma) (3 mg/kg mouse)-labelled platelets using an inverted fluorescence microscope (Axio Observer, Carl Zeiss MicroImaging GmbH, Germany) with a 5x objective connected to a Hamamatsu Orca-R2 charge-coupled device video camera. Platelet deposition and thrombus growth in injured venules were monitored until vessel occlusion defined as a complete arrest of blood flow for at least 5 minutes. Immediately after vessel occlusion, $20 \mu \mathrm{l}$ of saline containing rtPA $(80 \mu \mathrm{M})$ and hirudin $(10$ $\mu \mathrm{M})$ (Serbio) were applied topically in the chamber to enhance thrombolysis, and prevent rethrombosis. Thrombolysis was analyzed by measuring the occurrence of recanalization of occluded venules, the time to recanalization, and the decrease in thrombus area at 30 minutes and 1 hour after rtPA treatment. A total of 13 venules in 7 PN1 -/- mice and 13 venules in 7 WT mice were studied. Data acquisition and analysis were done using the Axiovision software (Carl Zeiss MicroImaging GmbH, Germany).

\section{Statistical analysis}

Results are shown as means \pm SEM. Students $t$ test was used for in vitro experiments with recombinant $\mathrm{PN}-1$, in vitro experiments of wild-type and $\mathrm{PN}$-1-deficient mice, and for lysis front velocity experiments. The one-way ANOVA followed by Dunnett's test was used when comparisons of anti-PN-1 IgG or anti-PAI IgG groups versus Control IgG were performed. A linear mixed-effects model (LME) was used for the analysis of in vivo thrombolysis. A $P$ value less than or equal to 0.05 was considered significant. 


\section{Results}

\section{PN-1 inhibits plasminogen activation by fibrin-bound tPA}

Plasminogen activation by tPA, was measured on a fibrin surface, in the presence or absence of recombinant PN-1. First, tPA was incubated for 1 hour on fibrin-coated plates, the excess of unbound tPA being eliminated. PN-1 was subsequently added to the fibrin-coated plates and the excess discarded. Plasmin generation induced by the residual fibrin-bound tPA was then determined after addition of plasminogen with the chromogenic substrate CBS0065. The initial rate of plasmin generation by tPA decreased by $~ 2$ fold in the presence of $\mathrm{PN}-1$ (Figure 1A): $2.7 \pm 0.3 \mathrm{nM}$ and $1.3 \pm 0.1 \mathrm{nM}$ plasmin were generated, respectively in the absence and presence of PN-1 (Figure 1B).

tPA-induced fibrin degradation was measured by fibrin-plasminogen-agar zymography with platelet releasates. Recombinant tPA induces a lysis area reflecting fibrinolytic activity relative to the amount of plasmin converted from plasminogen by tPA. As expected, the fibrin zymography lysis band corresponding to tPA was reduced by recombinant PN-1 (Figure 1C). No reduction in tPA induced-lysis area was observed after tPA incubation with the supernatant of resting human platelets. In contrast, when tPA was incubated with the secretion products of activated human platelets, the fibrin zymography lysis t-PA-band was barely detected, indicating the secretion of tPA inhibitor(s) by activated platelets (Figure 1C). To determine whether PN-1 contributed to fibrinolysis inhibition, zymography experiments were performed in the presence of a PN-1-blocking antibody. tPA activity was restored in the presence of the anti-PN-1 IgG (Figure 1C) but not in the presence of an irrelevant IgG (not shown). To confirm these findings, the same experiments were performed with platelets from PN-1-deficient mice and their littermate controls. Incubation of tPA with the secretion products of activated platelets from WT mice resulted in an almost complete inhibition of lysis (Figure 1D). On the contrary, the products secreted by platelets 
from PN-1-/- did not decrease the tPA-induced lysis area (Figure 1D). Together, these data demonstrate that $\mathrm{PN}-1$ has the remarkable capacity to inhibit the generation of plasmin induced by tPA bound to fibrin.

\section{PN-1 inhibits fibrin-bound plasmin}

Degradation of fibrin by the serine protease, plasmin, is a step in the fibrinolysis process where PN-1 can also play an important role. To test this hypothesis, plasmin activity was measured on a fibrin surface, in the presence or absence of recombinant PN-1. The initial rate of substrate hydrolysis induced by fibrin-bound plasmin decreased by $~ 10$-fold in the presence of PN-1 (Figure 2A-B). Fibrin-bound plasmin activity was thus drastically inhibited by $\mathrm{PN}-1$.

Plasmin-induced fibrin degradation was measured by using fibrin-agar zymography. Similarly to the results obtained with tPA, we observed that the secretion products of activated platelets inhibited plasmin-induced lysis. This inhibition was completely prevented by the blocking anti-PN-1 antibody (Figure 2C). Fibrin-agar zymography was also performed with platelets from PN-1-deficient mice and their littermate controls. Incubation of plasmin with the secretion products of activated platelets from WT mice resulted in an almost complete inhibition of lysis (Figure 2D). On the contrary, the products secreted by platelets from PN-1-/- mice did not reduce plasmin-induced lysis area (Figure 2D). Our results thus demonstrate that PN-1 secreted by activated platelets is able to inhibit the fibrinolysis induced by fibrin-bound plasmin

\section{Platelet PN-1 limits PRC lysis}

To test the functional effect of PN-1 on endogenous clot lysis, human platelet-rich plasma (PRP) containing FITC-fibrinogen, was preincubated with a control IgG or the 
blocking anti-PN-1 IgG before clotting. Fibrinolysis was then assessed by clot weight loss and fluorescence release from the clot after 24 hours at $37^{\circ} \mathrm{C}$. In the presence of a control IgG, clot weight loss was $7 \pm 1 \mathrm{mg}$, whereas preincubation with the anti-PN-1 IgG resulted in a large increase in clot weight loss, reaching $27 \pm 2 \mathrm{mg}$ (Figure 3A). A blocking anti-PAI-1 IgG also enhanced clot weight loss by $17 \pm 5 \mathrm{mg}$, although this increase was not statistically significant. The combination of both blocking antibodies resulted in a large increase in clot weight loss, reaching $46 \pm 10 \mathrm{mg}$ (Figure 3A). The percentage of FITC released from the clots was also significantly higher in the presence of the anti-PN-1 IgG (37 $\pm 2 \%$ ) than in the presence of an irrelevant IgG (26 $\pm 1 \%$ ) (Figure 3B). The same experiments were performed with PRP from WT and PN-1-deficient mice. Clot weight loss was greater for fibrinolysis with PN-1-/- clots (55 $\pm 6 \mathrm{mg}$ ) than with WT clots (31 $\pm 2 \mathrm{mg}$ ) (Figure 3C), and the percentage of released fluorescence was higher for PN-1 -/- (89 $\pm 3 \%)$ than for WT clots (64 $\pm 3 \%$ ) (Figure 3D). Together, these results show that, in the absence of PN-1, endogenous tPA-induced clot lysis is enhanced within 24 hours, indicating that platelet PN-1 is a regulator of endogenous clot lysis.

The effect of PN-1 inhibition or PN-1-deficiency on clot lysis was further investigated using a ROTEM ${ }^{\circledR}$ analyser. An exogenous supplement of a subthreshold lytic concentration of tPA $(0.5 \mathrm{nM})$ was used to induce clot lysis. As shown in Figures $4 \mathrm{~A}$ and $4 \mathrm{~B}$, the percentage of tPA-induced clot lysis was minimal in the presence of a control IgG, reaching $16 \pm 2 \%$, while it was greatly increased in presence of the anti-PN-1 IgG, reaching $42 \pm 5 \%$. A blocking antiPAI-1 IgG also has an increased tendency for clot lysis by $28 \pm 5 \%$, although it was statistically insignificant. The combination of both blocking antibodies resulted in an almost complete clot lysis at 60 minutes (91 $\pm 1 \%$ of lysis). To substantiate these results, experiments were also performed using mouse platelets (Figure 4C). The ROTEM ${ }^{\circledR}$ tracing showed that a subthreshold concentration of tPA induced lysis of WT clots by $56 \pm 7 \%$ 
whereas lysis of PN-1-deficient clots was almost complete (84 $\pm 8 \%$ ) under our experimental conditions (Figure 4D). These results indicate that both PN-1 and PAI-1 released by activated platelets contribute to inhibit tPA-induced clot lysis.

\section{Platelet $\mathrm{PN}-1$ reduces the velocity of clot lysis}

We visualized the lysis front of PRC by using laser scanning confocal microscopy (Figure 5). Addition of tPA at the edge of the microchambers of PRC initiated lysis with a straight and sharp front moving across the entire fibrin surface. A significant increase in the lysis front velocity was observed in the presence of the blocking anti-PN-1 IgG with an average rate of $22.5 \pm 2.8 \mu \mathrm{m} /$ minute compared to the control IgG $11.8 \pm 1.6 \mu \mathrm{m} /$ minute , $(P<$ $0.01 \mathrm{n}=5$ ) (Figure 5A). To confirm these findings, the same experiments were performed with clots from PN-1-deficient mice and their littermate controls. As observed with human clots, addition of tPA resulted in an acceleration of the lysis front in PN-1-deficient clots with a rate of $16.0 \pm 1.5 \mu \mathrm{m} /$ minute versus $10.3 \pm 0.9 \mu \mathrm{m} /$ minute with the WT clots $(P<0.05 \mathrm{n}=5)$ (Figure 5B).

\section{tPA-induced thrombolysis is enhanced in PN 1-/- mice.}

To determine whether the antifibrinolytic effect of PN-1 is of in vivo relevance, we have developed in mice, a method in which thrombolysis can be measured by intravital microscopy using the dorsal skinfold chamber model. We compared the efficiency of tPAinduced thrombolysis in WT and PN-1 -/- mice (Figure 6A). Topical application of $\mathrm{FeCl}_{3}$ over venules ranging from 130 to $160 \mu \mathrm{m}$ in diameter was used to induce vascular injury leading to occlusive thrombosis. While there was no significant difference in the occlusive thrombus size/area between WT and PN-1 -/- mice $\left(34163 \mu \mathrm{m}^{2} \pm 5459 \mu \mathrm{m}^{2}\right.$ vs $31656 \pm$ $4709 \mu \mathrm{m}^{2}, \mathrm{n}=13$ vessels from 7 mice per group), the time to reach complete occlusion was 
significantly reduced in PN-1 -/- mice compared to WT mice, in agreement with data obtained in the mesenteric vessel thrombosis model ${ }^{10}$. During the 24 hours following complete arrest of blood flow, spontaneous recanalization was observed in only 2 of 13 vessels out of 7 PN 1/-mice and in none of the 13 occluded vessels from WT mice. This indicates that spontaneous thrombolysis following $\mathrm{FeCl}_{3}$ injury is a slow process in both WT and PN1-/- mice. In order to accelerate thrombolysis, tPA was directly added to the chamber 5 minutes following complete vessel occlusion. Hirudin was simultaneously added to prevent rethrombosis. In WT mice, the mean time to recanalization following tPA treatment was superior to 1 hour while it was of $13 \pm 2$ minutes in PN-1 -/- mice ( $n=7$ mice) (Figure 6A). Furthermore, 1 hour after tPA treatment, the incidence of recanalization was $15 \%$ (2 of 13 vessels) in WT mice and reached $92 \%$ (12 of 13 vessels) in PN1 -/- mice (Figure 6B). Thirty minutes after tPA treatment, thrombus size remained unchanged in WT mice (101.6 $\pm 7.2 \%$ of initial size) whereas it was significantly reduced in PN-1 -/- mice (56.1 $\pm 8.5 \%$ of initial size). At 1 hour post-tPA treatment, the thrombus size was reduced in WT but this reduction was less important than in PN-1 -/- mice (76.7 $\pm 6.3 \%$ vs $42.8 \pm 9.5 \%$ of initial size) (Figure 6C). Altogether, these results confirm that PN1 is a potent inhibitor of tPA-induced thrombolysis in vivo.

After the thrombolysis experiments, mice were kept under observation for 24 hours and euthanized. Four hours after tPA treatment, all vessels occluded by $\mathrm{FeCl}_{3}$ injury were recanalized in both WT and PN1 -/- mice. Interestingly, all PN-1-deficient mice (7 out of 7) remained healthy the day following thrombolytic treatment, whereas 71\% (5 out of 7) of WT mice were apathetic and showed signs of respiratory distress. 


\section{Discussion}

In humans, platelet PAI-1 released locally after platelet activation is assumed to be a major contributor to the stabilization of the thrombus by inhibiting endogenous fibrinolysis ${ }^{5}$ ${ }^{6}$. However, PAI-1-independent mechanisms have also been proposed to contribute to platelet-dependent inhibition of fibrinolysis ${ }^{7}$. The existence of other non-PAI-1 proteinases inhibitors able to reduce plasminogen activation and/or plasmin activity has previously been suggested ${ }^{19}$. Our study also suggests a less important role for PAI- and reveals that an additional serpin plays an important role in inhibiting plasminogen activators and plasmin. Indeed, we show here for the first time that PN-1, which can accumulate at the sites of vascular injury due to its presence in platelets ${ }^{10}$, is an important player in the control of fibrinolysis. The fact that PN-1 can down-regulate both plasmin generation and plasmin activity on the fibrin matrix highlights the potential influence of PN-1 on fibrinolysis. Indeed, the fibrin matrix is largely recognized as an essential actor in the fibrinolysis process. It is well known that tPA-mediated plasminogen activation is dependent on fibrin, which restricts fibrinolysis to the site of thrombus ${ }^{20}$. Importantly, when bound to fibrin, tPA is protected from inhibition by PAI-1 ${ }^{21,22}$. The inhibition of tPA by PAI-1 is decreased by $80-90$ percent in the presence of fibrin, because PAI-1 has no access to the catalytic domain of fibrin-bound tPA $^{23}$. Moreover, the rate of inactivation of plasmin by $\alpha_{2}$-antiplasmin slows down very significantly when plasmin is bound to fibrin ${ }^{24}$. Thus, whereas serine proteases of the fibrinbound plasminergic system are "protected” from their principal inhibitors, platelet PN-1 appears to be one inhibitor capable of blocking them in situ. The blocking PAI-1 antibody alone led to a non significant increase in clot lysis, in agreement with previous data demonstrating that PAI-1-deficiency induced only mild hyperfibrinolysis ${ }^{19}$. This suggests that PAI-1 alone is not sufficient in regulating the lysis of platelet-rich clots. The higher fibrinolytic capacity observed in the presence of both PN-1 and PAI-1 blocking antibodies 
supports a synergic involvement of both proteins in the regulation of clot lysis. Moreover, platelet PN-1 can influence the lysis of fibrin clots generated spontaneously from PRP, without any exogenous tPA, but also after addition of recombinant tPA, indicating that PN-1 is inhibitory not only on endogenous but also on exogenous tPA-mediated lysis. These points are of clinical relevance: first, because endogenous fibrinolysis is known to play a pivotal role in the evolution of thrombotic cardiovascular diseases and second, because this may relate to the failure of optimal reperfusion in approximately one half of STEMI patients who are treated with fibrinolytic agents. A polymorphism in PN-1 could possibly explain the heterogeneity in the therapeutic efficacy of thrombolytic agents. Moreover, the fact that the lysis front moves faster when the PRC is devoid of PN-1, may imply that PRCs are refractory to tPA-induced lysis in a PN-1-dependent manner and that platelet PN-1 may have a critical impact at the level of fibers in the fibrin clot. Further experiments are needed to clarify this potential implication of platelet $\mathrm{PN}-1$ on clot structure.

PN-1 appears to be a particularly important actor both in the development and in the dissolution of a thrombus. Indeed, $\mathrm{PN}-1$ is involved in thrombus generation and extension by its capacity to inhibit thrombin-mediated fibrin formation and platelet activation ${ }^{10}$, and we demonstrate here that $\mathrm{PN}-1$ is also involved in thrombolysis by its capacity to inhibit the local generation and activity of plasmin. Because of these opposing effects, it was of great interest to analyze the effect of PN-1-deficiency in the process of thrombus dissolution, in vivo. For this purpose, we have developed an original murine model of in vivo thrombolysis associating ferric chloride injury and the dorsal skinfold chamber model. This approach is a reproducible method to quantify thrombus formation and lysis induced by a topical application of tPA. This device has the great advantage of allowing direct visualization, via intravital videomicroscopy, of thrombus formation but also, which is the originality of our model, of thrombus lysis in living animals. We observed that tPA-triggered PRCs are more readily lysed 
in PN-1-deficient mice than in WT mice, with both the rate and the extent of recanalization being increased in PN-1-/- mice. Our data thus demonstrate the important role of PN-1 in mediating the resistance of PRC to lysis. We also observed that WT mice poorly survived thrombolysis and exhibited a global organ failure syndrome, in contrast to PN-1-deficient mice which supported well the procedure without exhibiting any clinical manifestations.

The fact that platelet PN-1 is so important to protect the developing thrombus from premature lysis may explain the reason why the role of PAI-1 in thrombolysis resistance is a subject of controversy. Indeed, none of the previous investigations studying PAI-1 role in thrombolysis failure took into account the contribution of PN-1. We suggest here that endogenous PN-1 can play an important role in the failure of thrombolytic therapy to restore arterial blood flow. Clearly, our findings should be considered in the design of new therapeutic strategies, which should include the inhibition of PN-1 by antibodies or synthetic compounds to improve the therapeutic efficacy of thrombolytic agents. 


\section{Acknowledgments}

We thank Liliane Louedec for technical assistance, Julien Labreuche for the statistical analysis, and Dr Mary Osborne-Pellegrin for editing this paper.

\section{Funding Sources}

This work was supported by Inserm, Université Paris 7, and Fondation de France (grant 2009002497). Y.B. was supported by the Fondation pour la Recherche Médicale (FRM).

\section{Disclosures}

The authors have no conflicting financial interests. 


\section{References}

1. Alexandrov AV. Current and future recanalization strategies for acute ischemic stroke. J Intern Med. 2010;267:209-219.

2. Armstrong PW, Collen D. Fibrinolysis for acute myocardial infarction: current status and new horizons for pharmacological reperfusion, part 1. Circulation. 2001;103:2862-2866.

3. Hamsten A, de Faire U, Walldius G, Dahlen G, Szamosi A, Landou C, Blomback M, Wiman B. Plasminogen activator inhibitor in plasma: risk factor for recurrent myocardial infarction. Lancet. 1987;2:3-9.

4. Smith A, Patterson C, Yarnell J, Rumley A, Ben-Shlomo Y, Lowe G. Which hemostatic markers add to the predictive value of conventional risk factors for coronary heart disease and ischemic stroke? The Caerphilly Study. Circulation. 2005;112:3080-3087.

5. Levi M, Biemond BJ, van Zonneveld AJ, ten Cate JW, Pannekoek H. Inhibition of plasminogen activator inhibitor-1 activity results in promotion of endogenous thrombolysis and inhibition of thrombus extension in models of experimental thrombosis. Circulation. 1992;85:305-312.

6. Potter van Loon BJ, Rijken DC, Brommer EJ, van der Maas AP. The amount of plasminogen, tissue-type plasminogen activator and plasminogen activator inhibitor type 1 in human thrombi and the relation to ex-vivo lysibility. Thromb Haemost. 1992;67:101-105.

7. Fay WP, Eitzman DT, Shapiro AD, Madison EL, Ginsburg D. Platelets inhibit fibrinolysis in vitro by both plasminogen activator inhibitor-1-dependent and independent mechanisms. Blood. 1994;83:351-356. 
8. Baker JB, Gronke RS. Protease nexins and cellular regulation. Semin Thromb Hemost. 1986;12:216-220.

9. Mansuy IM, van der Putten H, Schmid P, Meins M, Botteri FM, Monard D. Variable and multiple expression of Protease Nexin-1 during mouse organogenesis and nervous system development. Development. 1993;119:1119-1134.

10. Boulaftali Y, Adam F, Venisse L, Ollivier V, Richard B, Taieb S, Monard D, Favier R, Alessi MC, Bryckaert M, Arocas V, Jandrot-Perrus M, Bouton MC. Anticoagulant and antithrombotic properties of platelet protease nexin-1. Blood. 2010;115:97-106.

11. Luthi A, Van der Putten H, Botteri FM, Mansuy IM, Meins M, Frey U, Sansig G, Portet C, Schmutz M, Schroder M, Nitsch C, Laurent JP, Monard D. Endogenous serine protease inhibitor modulates epileptic activity and hippocampal long-term potentiation. J Neurosci. 1997;17:4688-4699.

12. Jandrot-Perrus M, Lagrue AH, Okuma M, Bon C. Adhesion and activation of human platelets induced by convulxin involve glycoprotein VI and integrin alpha2beta1. J Biol Chem. 1997;272:27035-27041.

13. Fleury V, Angles-Cano E. Characterization of the binding of plasminogen to fibrin surfaces: the role of carboxy-terminal lysines. Biochemistry. 1991;30:7630-7638.

14. Lacave R, Rondeau E, Ochi S, Delarue F, Schleuning WD, Sraer JD. Characterization of a plasminogen activator and its inhibitor in human mesangial cells. Kidney Int. 1989;35:806-811.

15. Kufrin D, Eslin DE, Bdeir K, Murciano JC, Kuo A, Kowalska MA, Degen JL, Sachais BS, Cines DB, Poncz M. Antithrombotic thrombocytes: ectopic expression of urokinase-type plasminogen activator in platelets. Blood. 2003;102:926-933. 
16. Jones CI, Payne DA, Hayes PD, Naylor AR, Bell PR, Thompson MM, Goodall AH. The antithrombotic effect of dextran-40 in man is due to enhanced fibrinolysis in vivo. J Vasc Surg. 2008;48:715-722.

17. Collet JP, Montalescot G, Lesty C, Weisel JW. A structural and dynamic investigation of the facilitating effect of glycoprotein IIb/IIIa inhibitors in dissolving platelet-rich clots. Circ Res. 2002;90:428-434.

18. Lehr HA, Leunig M, Menger MD, Nolte D, Messmer K. Dorsal skinfold chamber technique for intravital microscopy in nude mice. Am J Pathol. 1993;143:1055-1062.

19. Carmeliet P, Stassen JM, Schoonjans L, Ream B, van den Oord JJ, De Mol M, Mulligan RC, Collen D. Plasminogen activator inhibitor-1 gene-deficient mice. II. Effects on hemostasis, thrombosis, and thrombolysis. J Clin Invest. 1993;92:27562760.

20. Hoylaerts M, Rijken DC, Lijnen HR, Collen D. Kinetics of the activation of plasminogen by human tissue plasminogen activator. Role of fibrin. J Biol Chem. $1982 ; 257: 2912-2919$.

21. Chmielewska J, Ranby M, Wiman B. Evidence for a rapid inhibitor to tissue plasminogen activator in plasma. Thromb Res. 1983;31:427-436.

22. Chmielewska J, Ranby M, Wiman B. Kinetics of the inhibition of plasminogen activators by the plasminogen-activator inhibitor. Evidence for 'second-site' interactions. Biochem J. 1988;251:327-332.

23. Keijer J, Linders M, van Zonneveld AJ, Ehrlich HJ, de Boer JP, Pannekoek H. The interaction of plasminogen activator inhibitor 1 with plasminogen activators (tissuetype and urokinase-type) and fibrin: localization of interaction sites and physiologic relevance. Blood. 1991;78:401-409. 
24. Kolev K, Lerant I, Tenekejiev K, Machovich R. Regulation of fibrinolytic activity of neutrophil leukocyte elastase, plasmin, and miniplasmin by plasma protease inhibitors. J Biol Chem. 1994;269:17030-17034. 


\section{Figure legends}

\section{Figure 1: Inhibition of fibrin-bound tPA activity by PN-1}

(A-B) tPA (2.5 nM) was bound to fibrin surfaces, and plasmin formation was recorded in absence or presence of recombinant PN-1 (10 nM), with the chromogenic substrate CBS0065. The curves represent the average of the raw data corresponding to the change in absorbance as a function of time in the absence and the presence of rPN-1. To simplify the plots, error standards are represented only every 20 or $40 \mathrm{~min}$. (B) Rates of substrate hydrolysis were calculated from the initial velocity and compared to a plasmin standard curve. Data are representative of 3 different experiments, each performed in triplicate. ${ }^{*} P<0.05$ significantly different from tPA alone. (C-D) Plasminogen activation by tPA was measured by fibrinplasminogen-agar zymography after incubation of tPA with the supernatant from resting platelets or activated platelets by PAR1-AP or PAR4-AP as described in Methods. tPA was incubated (C) with human platelet secretion products in the presence or absence of an antiPN-1 IgG, or (D) with platelet secretion products from WT and PN-1-/- mice. Data are representative of 5 separate experiments from different donors or mice.

\section{Figure 2: Inhibition of fibrin-bound plasmin activity by PN-1}

(A-B) Plasmin (50 nM) was bound to fibrin surfaces and its activity was measured in absence or presence of recombinant PN-1 (10 nM), with the chromogenic substrate CBS0065. The curves represent the average of the raw data corresponding to the change in absorbance as a function of time in the absence and the presence of rPN-1. To simplify the plots, error standards are represented only every 20 or $40 \mathrm{~min}$. (B) Rates of substrate hydrolysis were calculated from the initial velocity and compared to a plasmin standard curve. Data are representative of 3 different experiments, each performed in triplicate. ${ }^{* * *} P<0.001$ significantly different from plasmin alone. (C-D) Plasmin activity was measured by fibrin- 
agar zymography after incubation of plasmin with the supernatant from resting platelets or activated platelets by PAR1-AP or PAR4-AP as described in Methods. Plasmin was incubated (C) with human platelet secretion products in the presence or absence of an anti-PN-1 IgG, or (D) with platelet secretion products from WT and PN-1-/- mice. Data are representative of 5 separate experiments from different donors or mice.

\section{Figure 3: Effect of platelet PN-1 in PRC lysis}

(A-B) PRCs from PRP of healthy donors, in the presence of an irrelevant IgG or an anti-PN1 IgG, or an anti-PAI-1 IgG or (C-D) PRCs from WT or PN-1-/- mice PRP, were incubated with FITC-fibrinogen prior to clot formation. (A, C) The percentage reduction in clot weight and $(B, D)$ the percentage of released fluorescence were analyzed over 24 hours. Data are presented as means \pm SEM of 5 independent experiments from different donors and mice. ***P $<0.001$, significantly different from control IgG or WT clots. $* P<0.05$, significantly different from control IgG. ${ }^{* *} P<0.01$, significantly different from WT clots.

\section{Figure 4: Effect of platelet PN-1 on ROTEM $^{\circledR}$ ex vivo clot lysis.}

(A) Representative human PRP thromboelastogram $\left(\right.$ ROTEM $\left.^{\circledR}\right)$ profiles. PRP was preincubated with a subthreshold concentration of tPA in presence of an irrelevant IgG, or an anti-PN-1 IgG, an anti-PAI-1 IgG or both. (B) In each condition, the rate of fibrinolysis was assessed by the reduction of the amplitude of the thrombolelastogram profile at 60 minutes. (C) Representative mice PRP thromboelastogram $\left(\right.$ ROTEM $\left.^{\circledR}\right)$ profiles. WT and PN-1-/- PRPs were preincubated with a subthreshold concentration of tPA and (D) the rate of fibrinolysis was quantified at 60 minutes. Data are presented as means \pm SEM of 5 independent experiments from different donors and mice. ${ }^{* * *} P<0.001$, significantly different from control IgG. ${ }^{* * P}<0.01$ significantly different from WT clots. 


\section{Figure 5: Effect of platelet PN-1 on lysis-front velocity}

PRCs were labelled with Alexa 488-fibrinogen. (A) A series of confocal micrographs showing the dynamic lysis by rtPA, of human PRCs in presence of an irrelevant IgG or an anti-PN-1 IgG. (B) Confocal images of the dynamic lysis from WT or PN-1-/- PRCs. Progressive lysis-front motions are visualized and confocal micrographs are representative of 5 independent experiments from different donors and mice. Bar, $20 \mu m$.

\section{Figure 6: Effect of PN-1 on thrombolysis.}

(A) Representative intravital images of vessel recanalization after tPA-treatment following an occlusion induced by $\mathrm{FeCl}_{3}$. Bar, 200 $\mu$ m. (B) Quantification of the incidence of recanalized vessels within 1 hour post tPA-treatment. (C) Analysis of thrombus size after tPA-treatment in WT and PN-1 -/- mice. Data are means \pm SEM for 13 vessels injured in 7 mice per group. $* P<0.05$ significantly different from WT mice at equivalent time post-tPA treatment. 
A

\section{Figure 1}
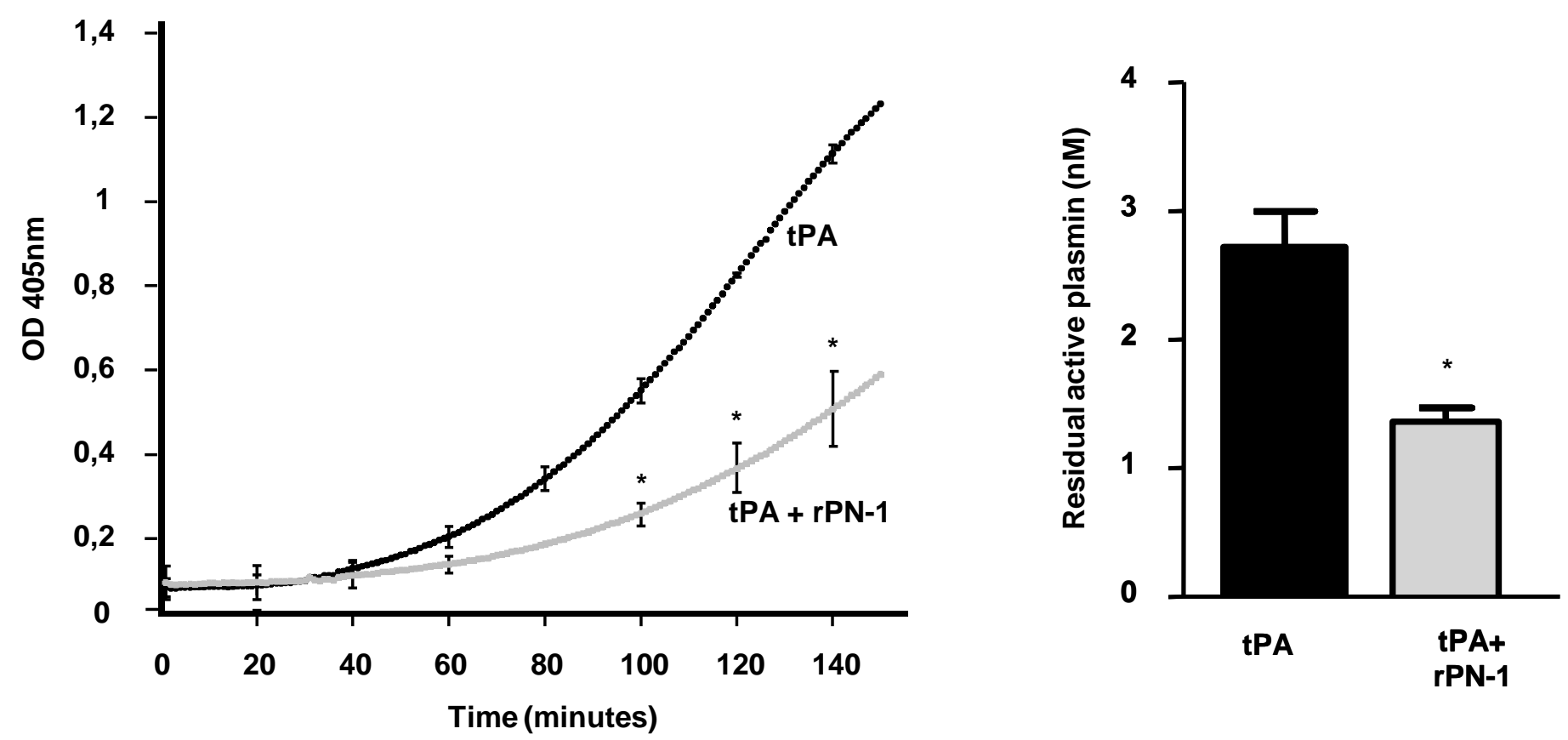

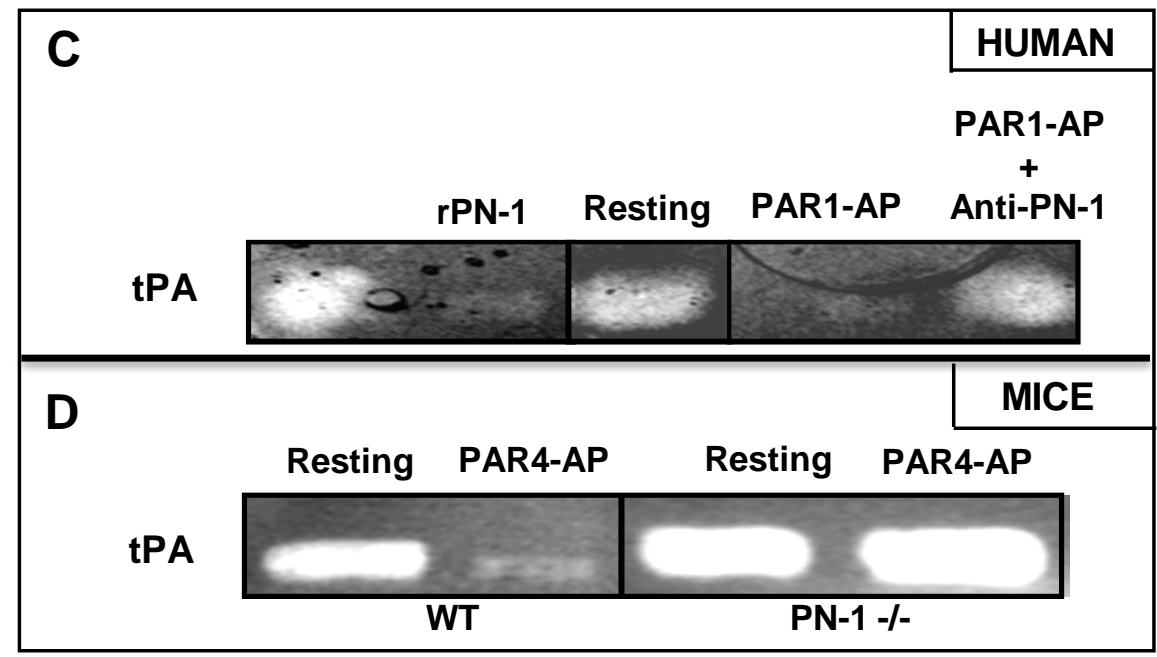


A

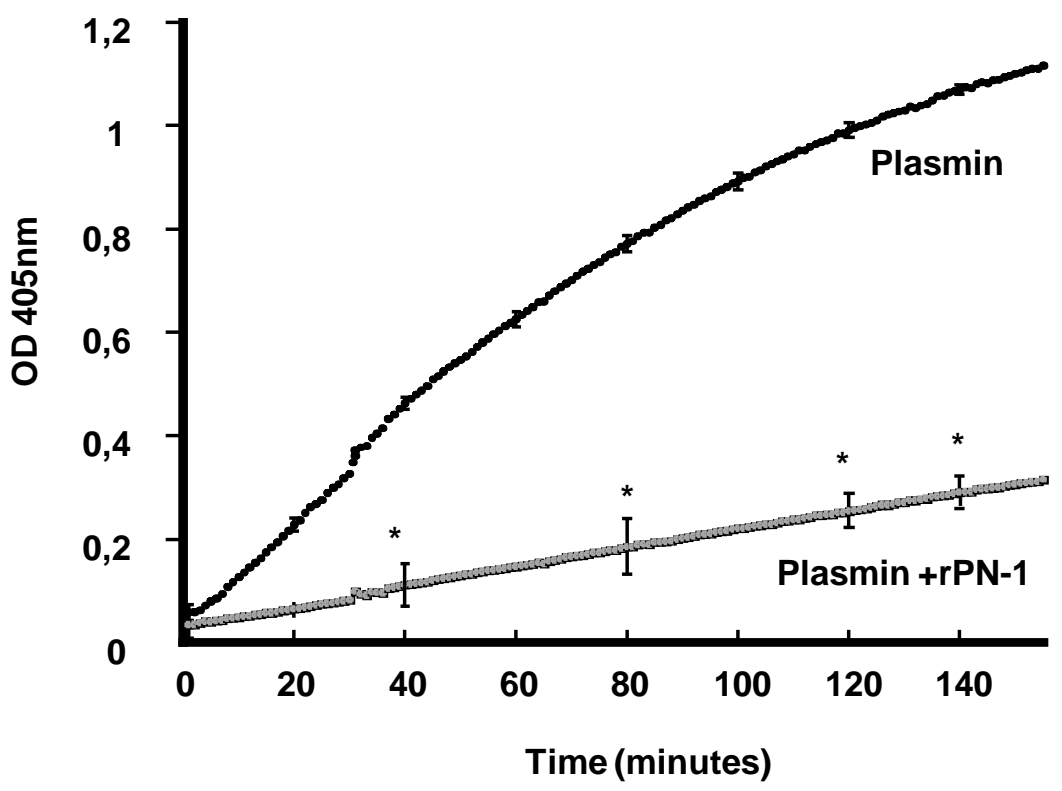

B

Figure 2

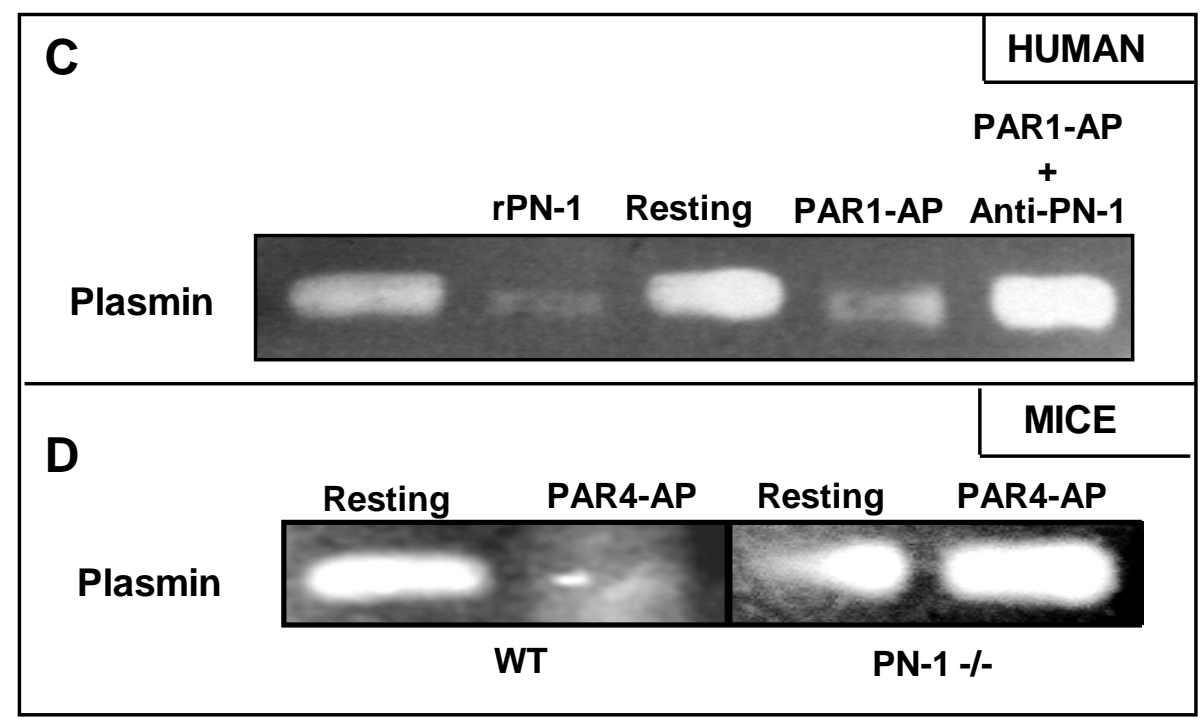



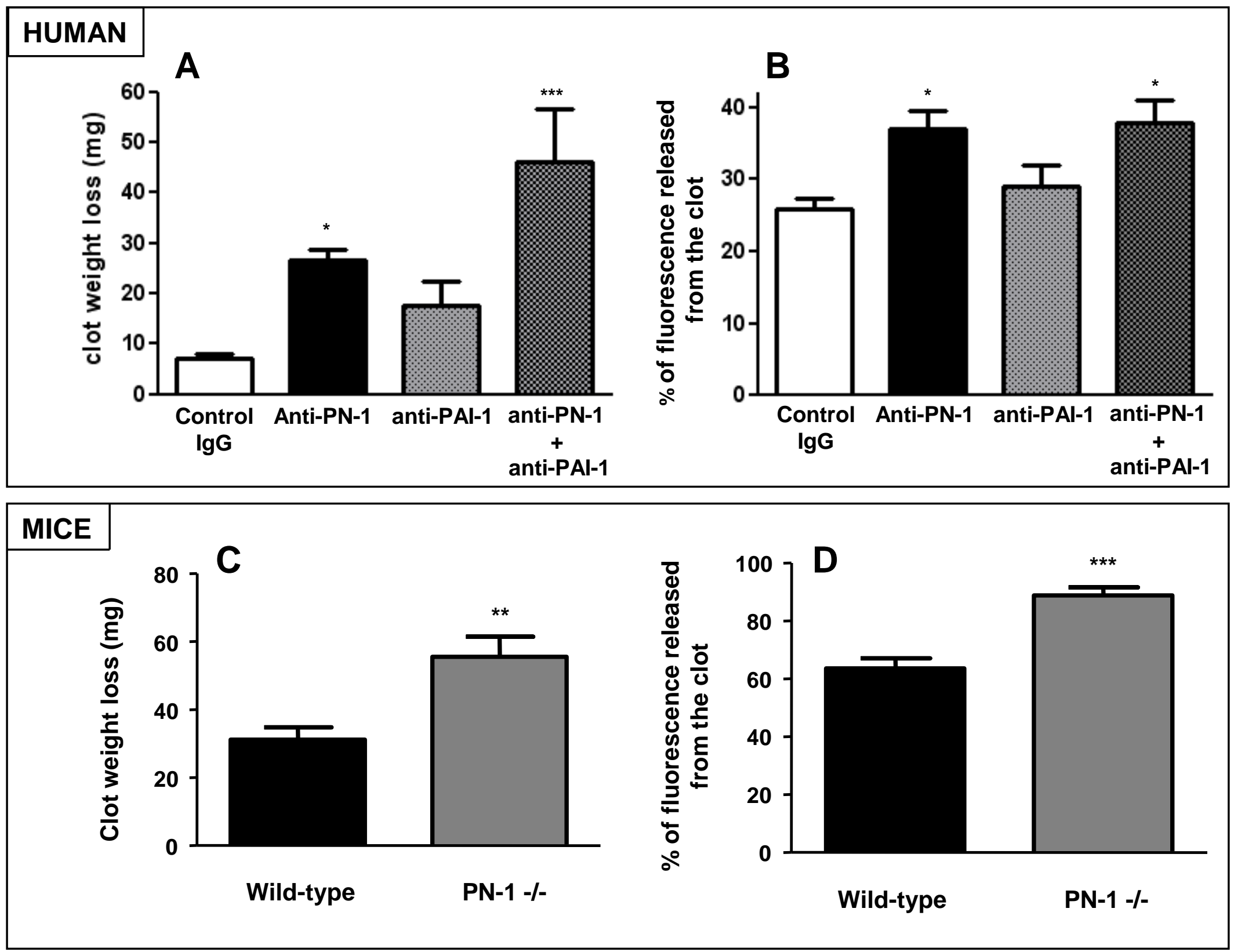
Figure 4

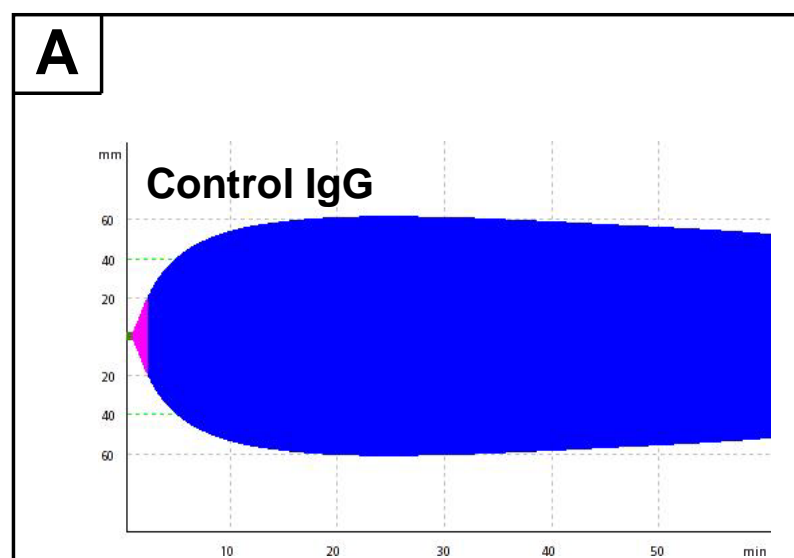

\section{HUMAN}
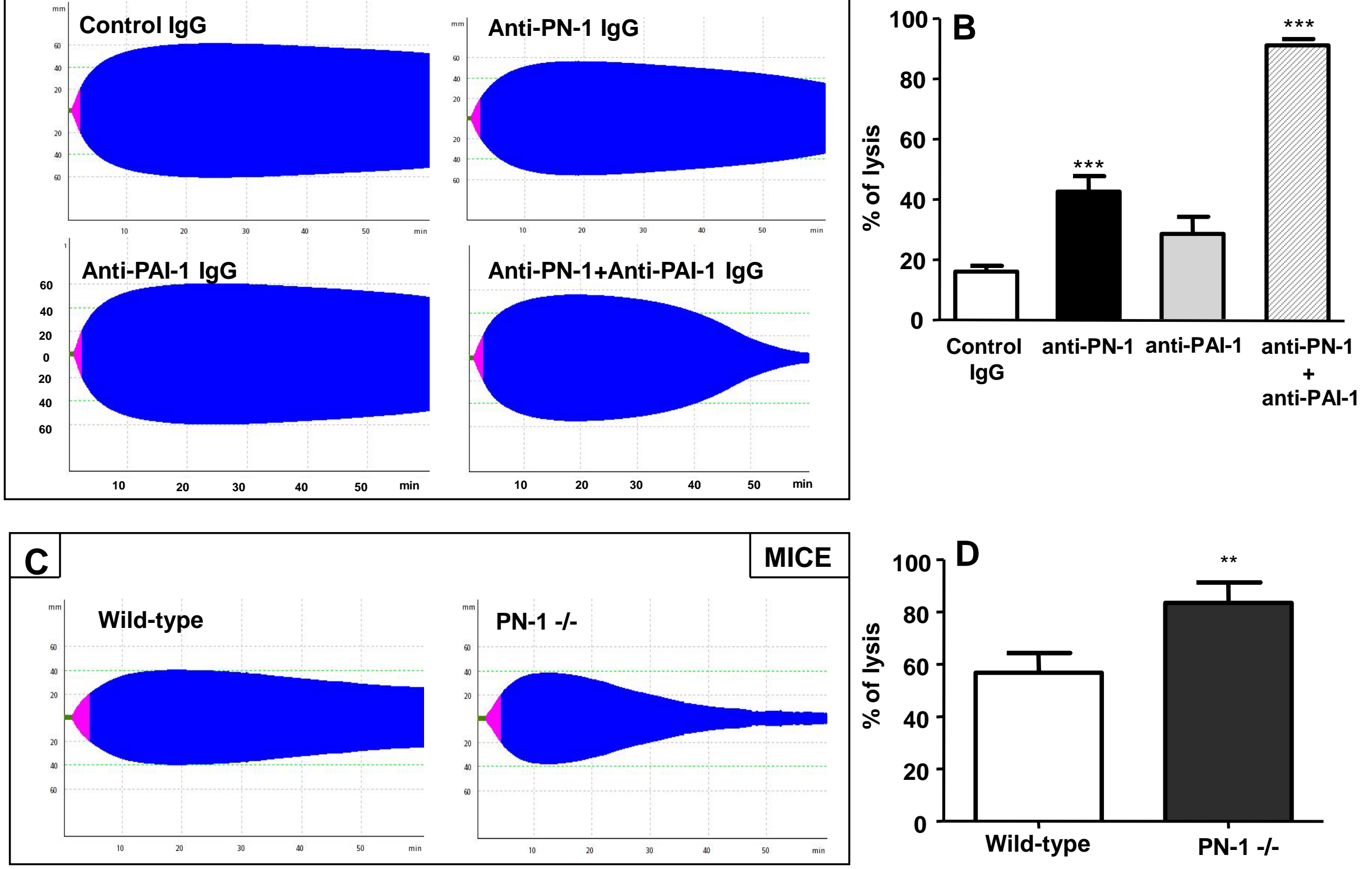
Figure 5

A

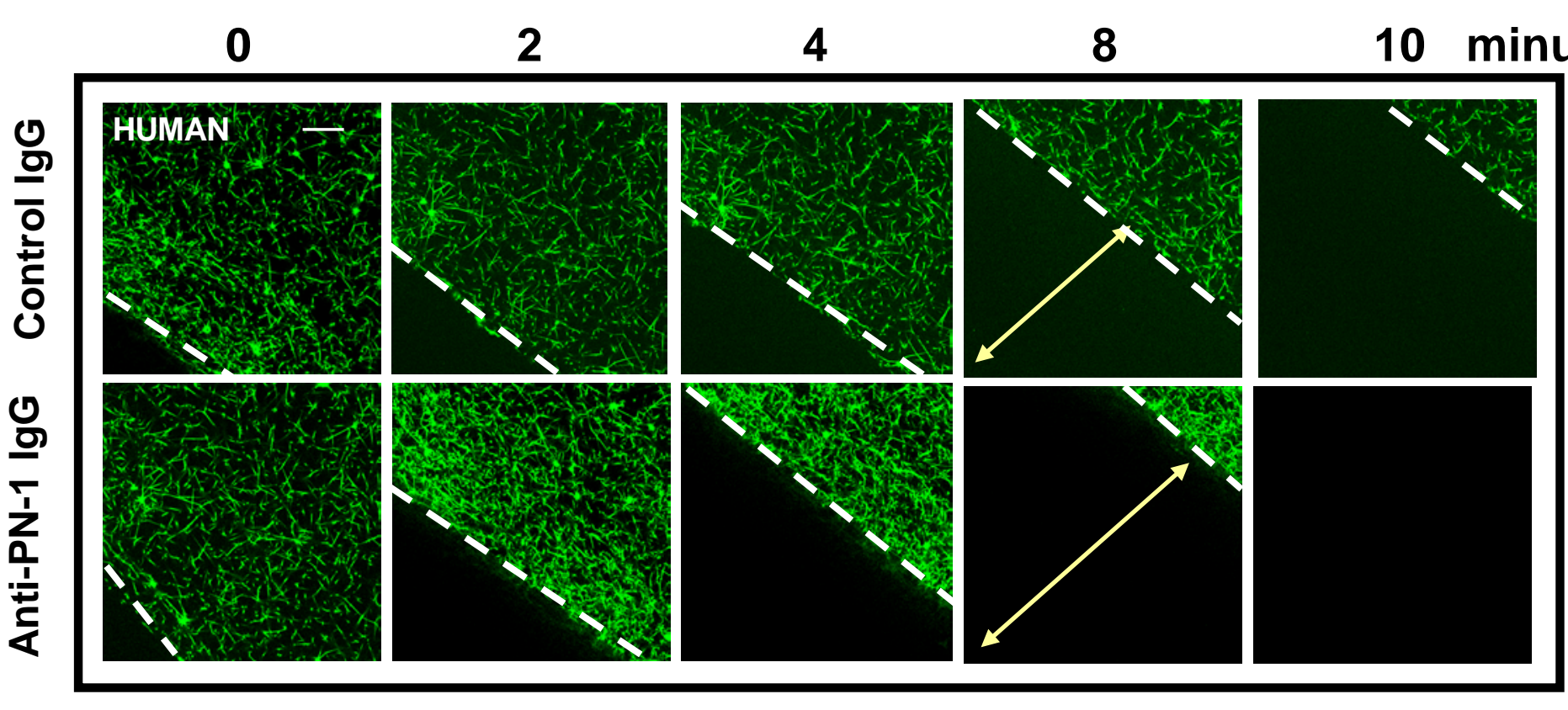

B

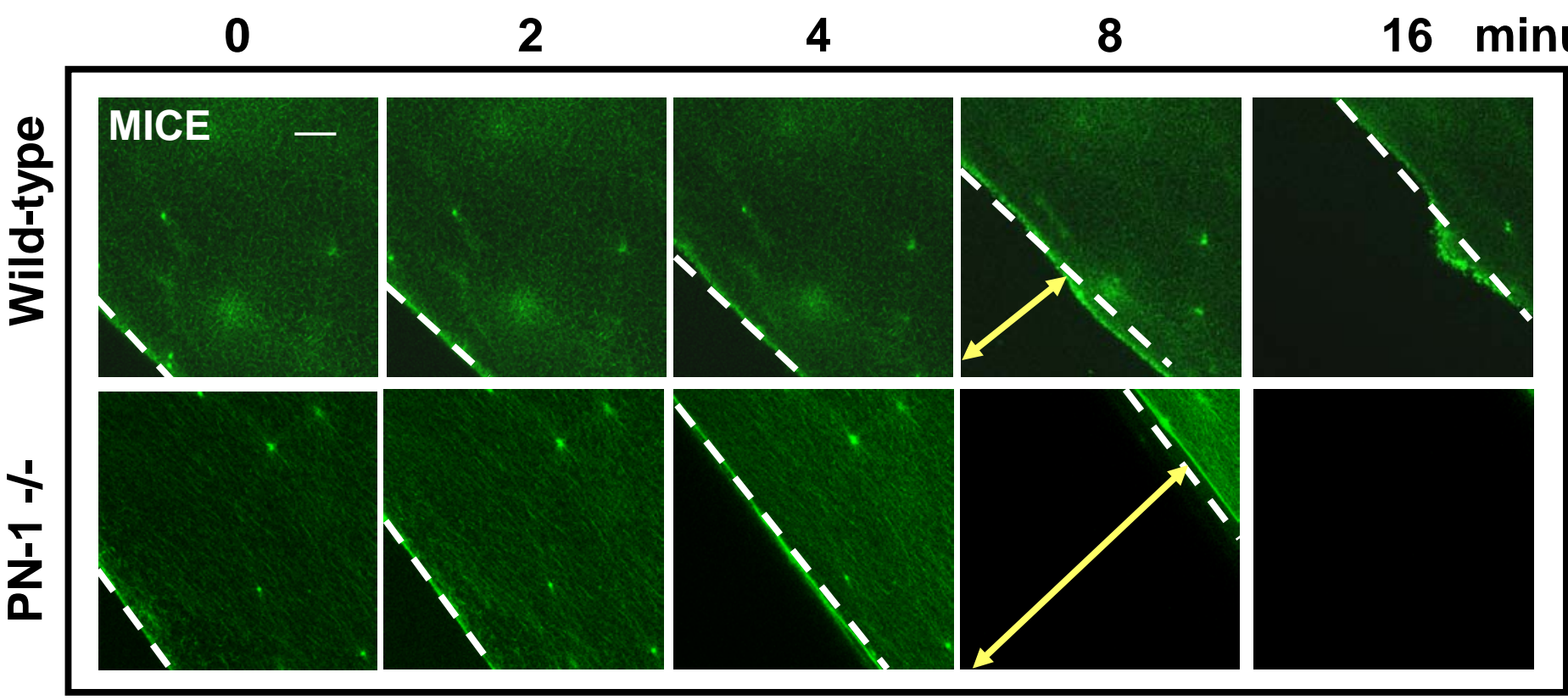


A
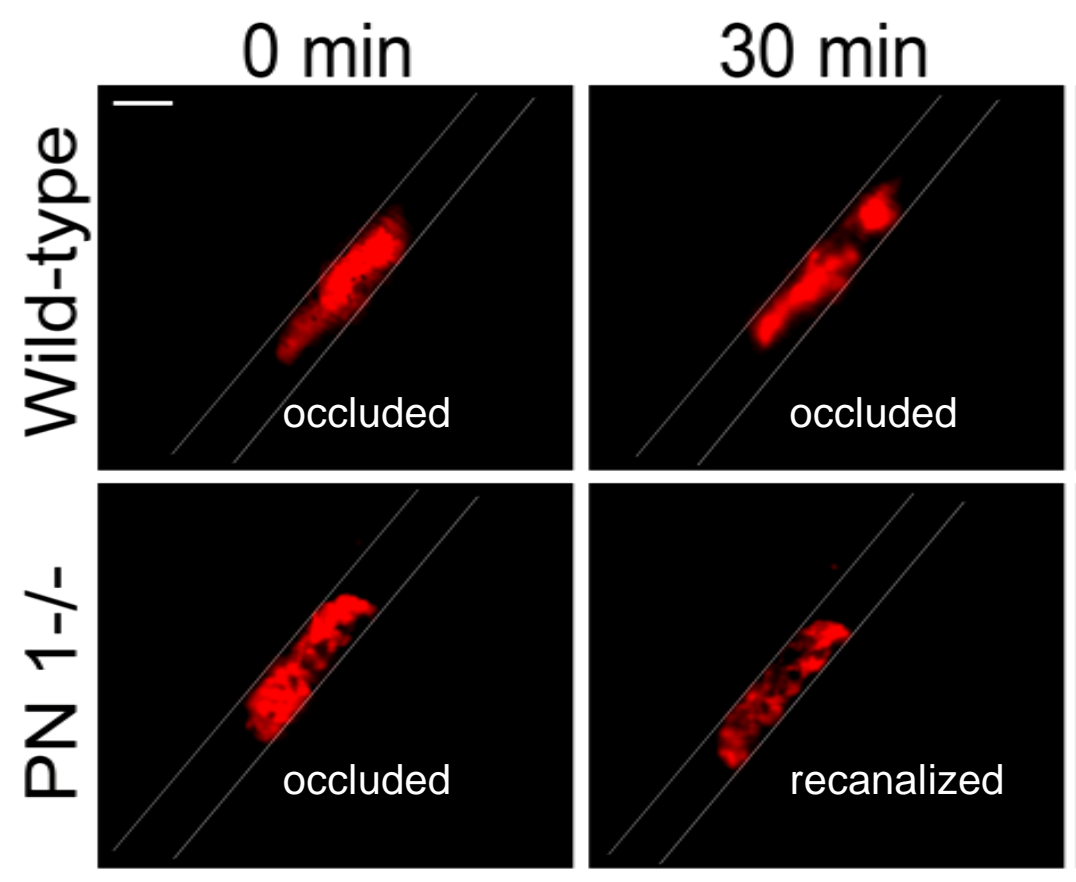

1 hour
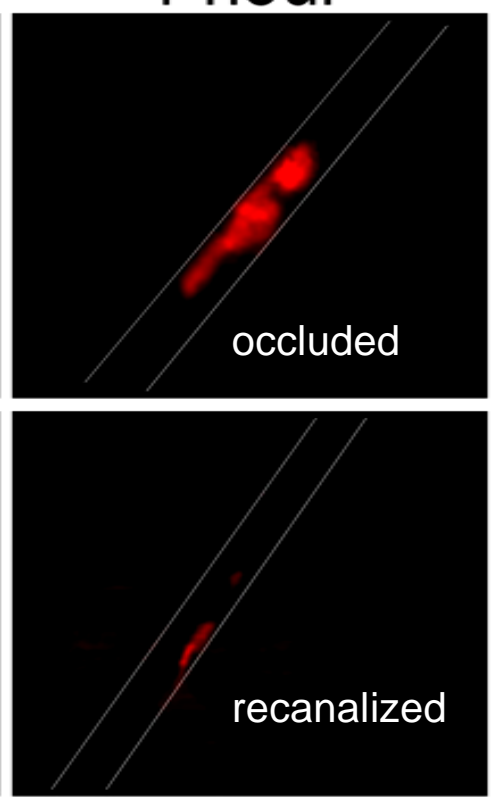

B

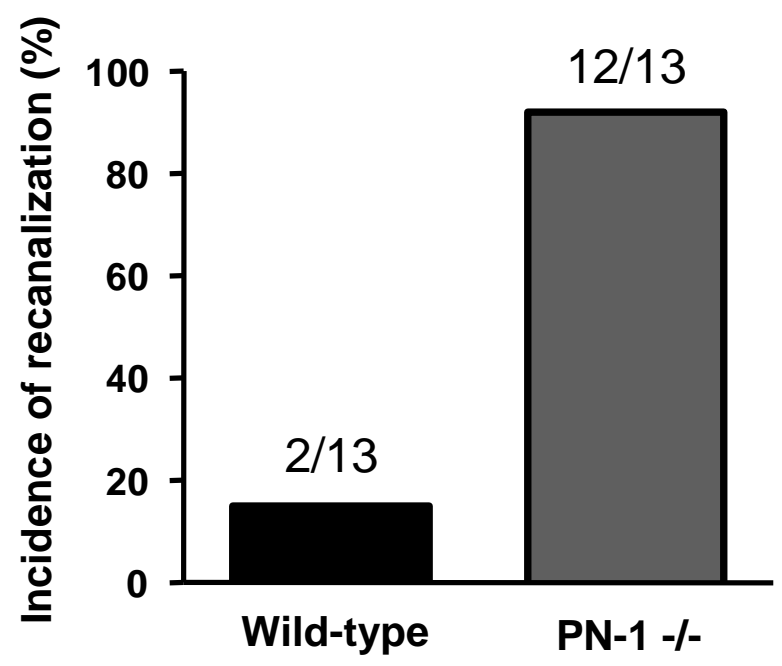

C

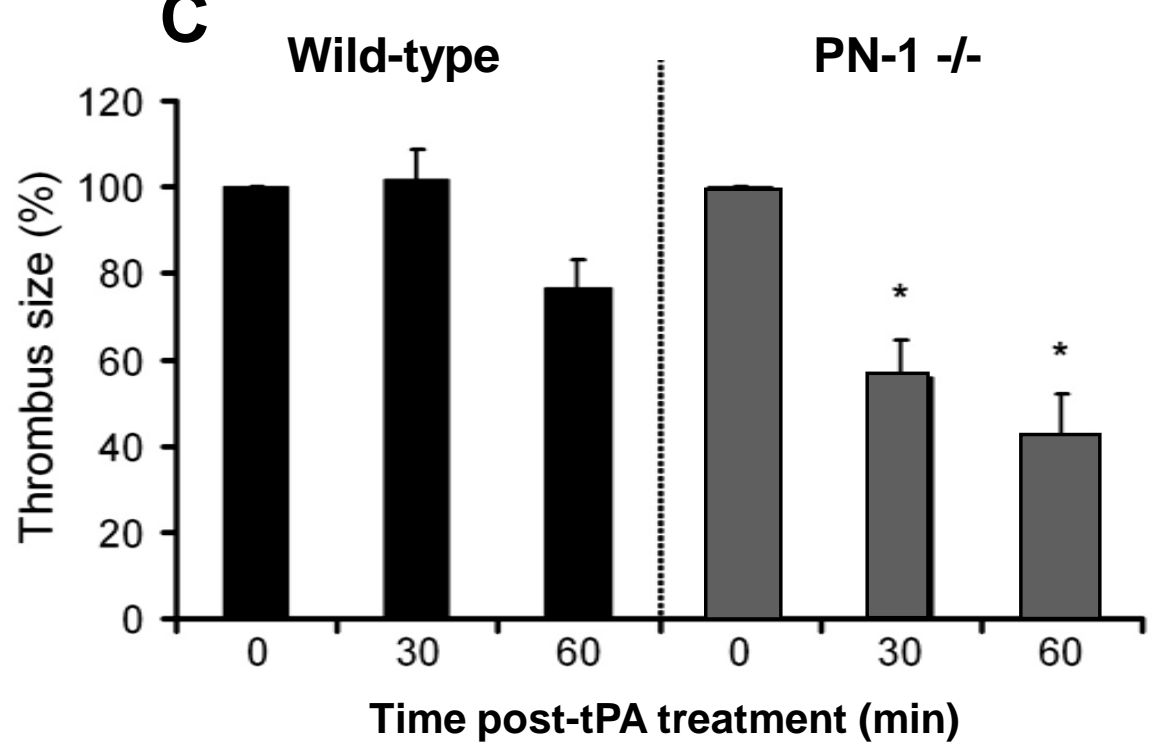

